1 Universidade Federal de Ciências da Saúde de Porto Alegre (UFCSPA) - Porto Alegre (RS), Brasil. lucilagutierrez@yahoo. com.br

${ }^{2}$ Centro Universitário Metodista IPA - Porto Alegre (RS), Brasil. neisare@yahoo.com.br

${ }^{3}$ Centro Universitário Metodista IPA, Programa de Pós-Graduação em Biociências e Reabilitação Porto Alegre (RS), Brasil. marcello.mascarenhas@ipa. metodista.br

\section{Caracterização de cuidadores de idosos da região metropolitana de Porto Alegre (RS): perfil do cuidado}

\author{
Characterization of caregivers of the elderly in the metropolitan \\ region of Porto Alegre (RS): care profile
}

Lucila Ludmila Paula Gutierrez', Neisa Rejane Machado Fernandes², Marcello Mascarenhas ${ }^{\mathbf{3}}$
RESUMO Este trabalho visa a caracterizar cuidadores de idosos da região metropolitana de Porto Alegre quanto a: capacitação para a profissão, seus sentimentos frente ao idoso, sobrecarga de trabalho, estado cognitivo e condição física. Entre janeiro e fevereiro de 2015, 20 participantes responderam a um questionário sobre idade, gênero, escolaridade, estado civil, breve investigação de estado de saúde e sentimentos frente ao cuidado e à Escala de Zarit Burden Interview, Escala de Depressão Geriátrica Abreviada, Mini Exame do Estado Mental, Escala de Avaliação do Equilíbrio e da Marcha de Tinneti. Verificou-se que as participantes nunca fizeram capacitação e apresentam perdas de saúde.

PALAVRAS-CHAVE Cuidadores. Esgotamento profissional. Avaliação em saúde.

ABSTRACT This study aims to characterize the caregivers of the elderly in metropolitan area of Porto Alegre regarding: the qualification for the profession, their feelings towards the elderly, the work overload, cognitive status and physical condition. Between January and February 2015, 20 participants answered a questionnaire about age, gender, education, marital status, brief health status investigation and feelings about care and the Zarit Burden Interview Scale, Geriatric Depression Scale, Mini-Mental State Examination, Tinneti's Balance and Gait Assessment Scale. It was verified that the participants have never done training and that they present losses in their health.

KEYWORDS Caregivers. Burnout professional. Health evaluation. 


\section{Introdução}

O Brasil se encontra em um momento de transição demográfica em que se observam mudanças na pirâmide populacional, favorecendo o envelhecimento da população. Claramente, as alterações fisiológicas advindas da terceira idade podem levar o idoso a necessitar de auxilio em atividades que antes pareciam de simples execução. É daí que surge o cuidador de idoso, o qual, muitas vezes, não possui capacitação para exercer tal função, resultando em desgaste para o ser cuidado e para o cuidador (PAVARINI; LOUREIRO; SOUZA, 2011; SOUZA, 2016). Carneiro e França (2011) apontam que, no Brasil, 1/3 dos idosos $(33,2 \%)$ reside com seus cônjuges, quase a metade $(44,6 \%)$ mora com os filhos, outros tantos $(21,2 \%)$ residem com parentes e $1 \%$ mora com não parentes, de onde surge o cuidador familiar. Embora se tenha na família o recurso mais importante para a manutenção do bem-estar do idoso, as famílias, que tinham por hábito o cuidado dos idosos, têm mudado rapidamente, e novos arranjos vêm sendo construídos, entre eles, a transferência dos cuidados de seus entes envelhecidos para Instituições de Longa Permanência para Idosos (REBOUÇAS; PEREIRA, 2008) ou instituições com características híbridas, como as chamadas Day Home, que se dispõem a cuidar do idoso fora de seu domicílio por período diário, sem pouso. Isso se dá porque o cuidado prestado ao idoso exige dedicação exclusiva e quase sempre integral, baseado nas suas necessidades (ARAúJO ET AL., 2013), o que pode levar à fragilização do cuidador em decorrência dos sentimentos de ansiedade e de estresse (MARIGLIANO ET AL., 2015). Identificar os fatores que predispõem o cuidador de idosos à fragilidade abre espaço para a discussão de estratégias que podem ser desenvolvidas para minorá-los, minimizando os custos ao setor público, beneficiando os cuidadores e aqueles que dependem de seus cuidados (TOMOMITSU; LEMOS; PERRACINI, 2010). Nesse contexto, é de suma importância que se conheça o universo dos cuidadores, assim como seu relacionamento com o idoso. Portanto, o objetivo deste trabalho foi caracterizar os cuidadores de idosos que procuraram uma instituição de atendimento diário a idosos (Day Home) na região metropolitana de Porto Alegre, no período de janeiro a fevereiro de 2015, quanto à capacitação para o exercício da profissão, aos seus sentimentos frente ao idoso, à sobrecarga de trabalho e/ ou estresse, ao estado cognitivo e à condição física dos mesmos.

\section{Material e métodos}

Neste trabalho, foi realizado um estudo qualiquantitativo observacional, transversal e descritivo. A amostra foi constituída por cuidadores de idosos que procuraram uma Day Home com a finalidade de orientação, atendimento aos idosos ou vaga de trabalho, na região metropolitana de Porto Alegre (RS), e que, a convite dos pesquisadores, assinaram o Termo de Consentimento Livre e Esclarecido (amostragem por conveniência) (FLETCHER; FLETCHER; FLETCHER, 2014). O estudo foi realizado na referida instituição nos meses de janeiro e fevereiro de 2015. A coleta de dados ocorreu após aprovação do Comitê de Ética em Pesquisa do Centro Universitário Metodista IPA, CAAE 38298114.6.0000.5308.

Foram aplicados questionários semiestruturados contendo questões abertas e fechadas, respondidos na forma de entrevista gravada por um pesquisador previamente treinado, em sala individualizada na própria Day Home, com, aproximadamente, 15 minutos para cada questionário, sem intervenção externa, minimizando possíveis constrangimentos por parte do entrevistado. As variáveis pesquisadas foram: idade; gênero; escolaridade; estado civil e breve investigação de estado de saúde - que incluiu perguntas sobre o peso e a altura do cuidador de idosos, para medida do Índice de Massa Corporal (IMC), presença de 
doenças prévias devidamente diagnosticadas por médicos e tempo de doença prévia, de modo a compor um rápido histórico de saúde do cuidador. Também se questionou sobre tempo de ocupação como cuidadores de idosos; motivos que os levaram a escolher essa função; o que os agrada e desagrada nessa colocação; se trocariam esse cargo se tivessem oportunidade; carga de trabalho semanal; se já se irritaram uma vez ou mais com o idoso cuidado e as principais causas; $\mathrm{e}$ se fizeram alguma capacitação para exercer a função. Para verificar se havia sobrecarga de trabalho e/ou estresse, utilizou-se a Escala de Zarit Burden Interview (ZBI), composta por 22 questões que avaliam a saúde, as vidas social e pessoal, a situação financeira, o bem-estar emocional, as relações interpessoais e o ambiente do cuidador (SEQUeIRA, 2010). Também se aplicou a Escala de Depressão Geriátrica Abreviada, para obtenção de informações sobre o estado cognitivo dos cuidadores e para observação de aspectos e graus depressivos nos entrevistados. A Escala de Depressão Geriátrica resulta de um questionário de quinze perguntas, em que cada resposta positiva soma um ponto. Desse somatório, avalia-se como estado normal resultados de 0 a 5 pontos; depressão leve entre 6 e 10 pontos; e, de 11 em diante, depressão severa (PARADELA; LOURENÇO; VERAS, 2005). Com a finalidade de traçar indícios de alterações mentais e neurológicas, levando-se em consideração o tempo de estudo de cada cuidador de idosos, foi utilizada a escala Mini Exame do Estado Mental (Minimental - Meem), com quinze questões respondidas com 'sim' ou 'não', que vão somando pontos. Foram avaliados domínios de orientação temporal, espacial, memória imediata e de evocação, cálculo, linguagem, nomeação, repetição, compreensão, escrita e cópia do desenho, em que a demência cognitiva é sugerida para escores abaixo de 28 pontos em indivíduos com mais de sete anos de escolaridade; e, menos de 24 pontos para aqueles indivíduos que possuem entre quatro e sete anos de escolaridade (FOLSTEIN; FOLSTEIN; MCHUGH, 1975).

Por fim, foi realizada Avaliação de Equilíbrio e Marcha de Tinetti para observação da condição física dos cuidadores de idosos, com uma escala de 16 tarefas, que são avaliadas por meio da observação do examinador. A cada tarefa, a resposta pode ser classificada como: normal (0), adaptável (1) e anormal (2). São atribuídos pontos de 0-2 na realização das tarefas, totalizando, no máximo, 48 pontos. Valores abaixo de 19 pontos e entre 19 e 24 pontos representam, respectivamente, risco moderado e alto risco de quedas (FIGUEIREDO; LIMA; GUERRA, 2007).

Os dados obtidos foram organizados em um banco de dados do $\operatorname{Excel}^{\circledR}$ (versão 2010) e analisados na forma de tabelas e gráficos, sendo descritos como valores absolutos e percentuais.

\section{Resultados}

A amostra deste estudo foi constituída por 20 mulheres cuidadoras de idosos, sendo que 15 delas são consideradas profissionais da área, e 5 que cuidam de familiares. Todas nasceram no estado do Rio Grande do Sul. Apenas 25\% delas não moram com a própria família, sendo a minoria casada. A escolaridade prevalente na população estudada é o ensino médio completo. Ainda, a faixa etária das cuidadoras de idosos se encontra acima de 50 anos. Esses dados podem ser visualizados na tabela 1 . 
Tabela 1. Características das cuidadoras de idosos entrevistadas que procuraram uma instituição de atendimento diário a idosos (Day Home), na região metropolitana de Porto Alegre, no período de janeiro e fevereiro de 2015

\begin{tabular}{llrr}
\hline Variável & Categoria & № casos & \% \\
\hline Gênero & Feminino & 20 & 100 \\
& Masculino & 0 & 0 \\
\hline Estado Civil & Casado(a) & 8 & 40 \\
& Solteiro(a) & 4 & 20 \\
& Viúvo(a)/divorciado(a) & 8 & 40 \\
\hline Escolaridade & Fundamental & 6 & 30 \\
& Médio & 8 & 40 \\
& Superior incompleto & 5 & 25 \\
& Superior completo & 1 & 5 \\
\hline Nascimento & Rio Grande do Sul & 20 & 100 \\
\hline Faixa Etária & $31-40$ anos & 2 & 10 \\
& $41-50$ anos & 5 & 25 \\
& $51-60$ anos & 12 & 60 \\
\hline & Acima de 60 anos & 1 & 5 \\
\hline
\end{tabular}

Quanto ao tempo de ocupação, 46\% das cuidadoras de idosos (familiares ou profissionais) que participaram deste estudo trabalham na área há pelo menos 5 anos (figura 1).

Figura 1. Tempo de ocupação das cuidadoras de idosos entrevistadas que procuraram uma instituição de atendimento diário a idosos (Day Home), na região metropolitana de Porto Alegre, no período de janeiro e fevereiro de 2015
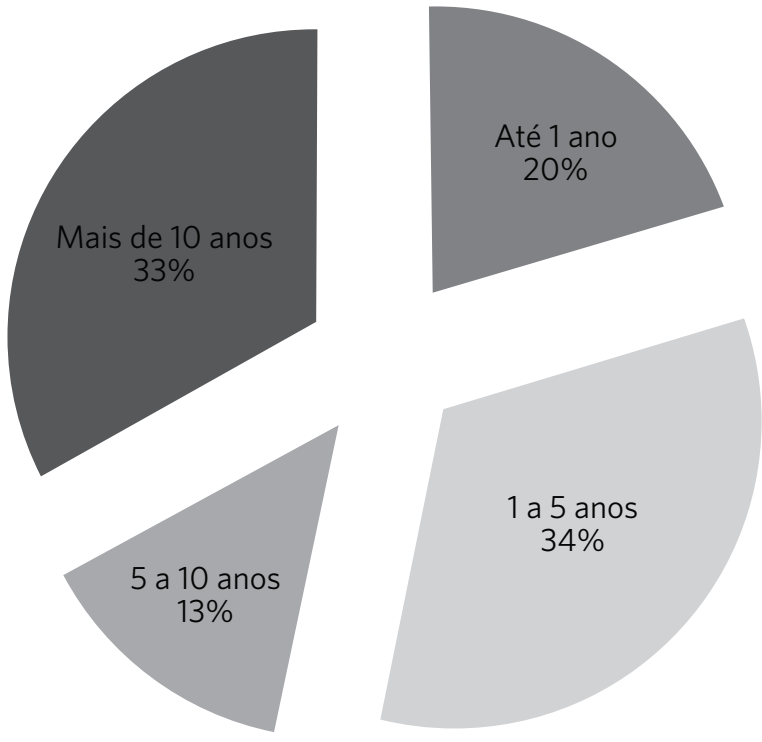
Com relação as cuidadoras de idosos que exercem essa profissão ( $n=15$ ), quando questionados os motivos que as levaram a desempenhar tal atividade, $13 \%$ das entrevistadas relataram já ter trabalhado com crianças e que acreditam que essa função seja semelhante à de cuidar de idosos; $20 \%$ declararam gostar de idosos; $27 \%$ expuseram que ocuparam a função ao acaso; e $40 \%$ por necessidade financeira. Das entrevistadas, $53 \%$ revelaram exercer o ofício por opção. Nenhuma delas fez capacitação ou estudou para se tornar cuidadora profissional de idosos. A respeito do que mais as agrada em sua ocupação, 13\% afirmaram se sentirem úteis auxiliando as pessoas, $20 \%$ declararam gostar de realizar tarefas operacionais (como dar banho, cuidar da alimentação e levar os idosos para caminhar), 27\% referiram que aprendem coisas novas com os idosos e $40 \%$ expuseram que se sentem gratificadas pelo afeto que recebem como retorno. Por outro lado, quando foi questionado sobre o que mais as desagrada na sua função, 33\% relataram que é a interferência dos familiares na sua maneira de cuidar, 20\% afirmaram que era a falta de conhecimento para ocupar esse cargo e $20 \%$ referiram ser a teimosia ou a demência do paciente. A maioria das entrevistadas $(60 \%)$ relatou já ter se irritado com o idoso cuidado apenas uma vez, $11 \%$ de uma a cinco vezes, $11 \%$ por mais de cinco vezes, e o restante (18\%) declarou nunca ter se irritado. Entre as causas da irritação estão os desentendimentos com os familiares dos idosos (22\%), o desconhecimento das patologias que acometem os idosos (33\%) e não saber lidar com a teimosia do paciente (45\%). Em função da baixa remuneração e do excesso de trabalho, $20 \%$ das cuidadoras profissionais expuseram que trocariam de ocupação se tivessem oportunidade.

Essas mesmas questões foram feitas às cuidadoras de idosos que são familiares de seus entes envelhecidos $(n=5)$. Duas delas cuidam das sogras, duas cuidam de suas mães, e uma cuida do pai. As cinco responderam que não se preparam para a tarefa de cuidadora com cursos ou especializações para exercer a função, mas relataram que, sempre que podem, buscam em leituras e programas vespertinos de televisão elucidações para suas dúvidas, assim como quando acompanham o idoso ao médico, sendo que duas prestam cuidados $24 \mathrm{~h}$ por dia, outras duas atendem $12 \mathrm{~h}$ por dia, e uma atende 8 horas ao dia. Destas, ainda, quatro disseram que as folgas ficam para 'quando der' e que elas são usadas para as lidas domésticas, para visitarem outros parentes e/ou amigos ou resolverem problemas particulares. Nenhuma delas optou pela tarefa em família. Com relação ao motivo que as levou a cuidar de seu familiar idoso, todas afirmaram que se sentiam na 'obrigação’ de fazê-lo. Quanto ao que mais as agrada na referida função, 80\% das cuidadoras declararam que é a proximidade/convivência com o idoso, e $20 \%$ afirmaram que ficam felizes quando percebem que em seu atendimento existe troca de afeto e aprendizagem. O que mais desagrada as cuidadoras de parentes idosos é a ‘teimosia' do(a) idoso(a) e a cobrança da sociedade sobre elas. Todas admitiram já terem se irritado com seus(suas) familiares idosos(as) por mais de uma vez, sendo os principais motivos citados a falta de atitude do idoso perante a vida, ocorrências cotidianas (como colocar 'meias trocadas' ou 'se sujar após o banho') e, ainda, não querer ficar na casa de outro parente. Quando indagadas pelo pesquisador se gostariam de trocar essa função com alguém, duas cuidadoras, categoricamente, responderam que sim, justificando que se sentiriam melhores perante o idoso e os demais familiares; uma não soube dizer; e duas afirmaram que gostariam de revezar os cuidados de seus parentes idosos, mas que têm medo de que os cuidadores que assumirem a função não saibam tratar os idosos como elas os tratam.

Para análise da condição física, foi realizada uma breve investigação de estado de saúde das cuidadoras, e encontrou-se que, do total das 20 cuidadoras de idosos, $45 \%$ se encontravam eutróficas, $20 \%$ com sobrepeso e $35 \%$ com obesidade. Com relação a diagnósticos 
médicos de doenças pregressas, $60 \%$ delas admitiram possuir patologias identificadas. O tempo de diagnóstico variou de até um ano para $18 \%$, de um a cinco anos para $41 \%$, e de cinco a dez anos também para $41 \%$. Com referência ao aparelho respiratório, a queixa mais referida foi tosse (sete cuidadoras de idosos). Já no aparelho cardiovascular, para oito cuidadoras, as queixas foram de cansaço durante os esforços relativos à função que exercem, palpitações para três delas, e edema nos membros inferiores para sete cuidadoras. Metade das entrevistadas relatou mais de um desses últimos sintomas citados. Para os sintomas do aparelho locomotor, as dores articulares foram as principais queixas, contemplando a totalidade das entrevistadas, sendo que oito delas referiram dores nos joelhos, duas relataram dores nos ombros, e duas citaram dores lombares. No aparelho digestório, sete cuidadoras de idosos queixaram-se de azia constante, quatro referiram sensação de queimação epigástrica, e uma citou dor epigástrica.

A figura 2 apresenta os percentuais de carga de trabalho semanal das cuidadoras profissionais ( $\mathrm{n}=15)$ e de idosos familiares ( $\mathrm{n}=5$ ), de onde se depreende que, em geral, elas trabalham intensamente.

Figura 2. Carga de trabalho semanal, em dias, das cuidadoras de idosos entrevistadas que procuraram uma instituição de atendimento diário a idosos (Day Home), na região metropolitana de Porto Alegre, no período de janeiro e fevereiro de 2015

Trabalho Semanal

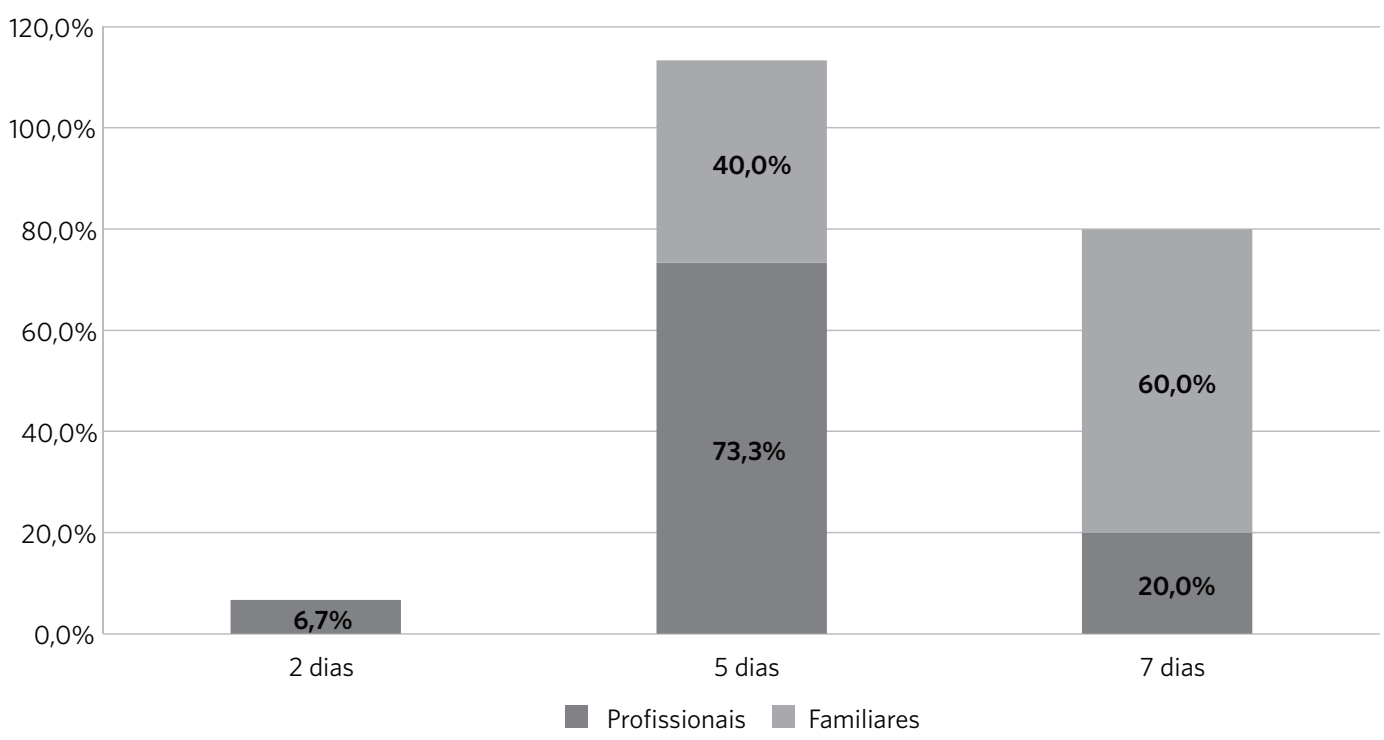

Por meio do questionário para escala de percepção de sobrecarga de trabalho e/ou estresse (ZBI), buscaram-se informações sobre essas cuidadoras de idosos nos aspectos psicológico e afetivo. A ZBI é uma escala composta por 22 itens que avaliam a relação cuidador-paciente, a condição de saúde, o bem-estar psicológico, as finanças e a vida social (SEQUEIRA, 2010). Tais dados estão representados na tabela 2 . 
Tabela 2. Avaliação da percepção das cuidadoras de idosos entrevistadas que procuraram uma instituição de atendimento diário a idosos (Day Home) sobre a sua sobrecarga de trabalho e os aspectos psicológicos e afetivos (escala de Zarit Burden Interview), na região metropolitana de Porto Alegre, no período de janeiro e fevereiro de 2015

\begin{tabular}{|c|c|c|c|c|c|c|c|c|c|c|}
\hline \multirow{2}{*}{$\begin{array}{l}\text { Questões para escala de percepção de sobrecarga } \\
\text { de trabalho e/ou estresse e aspectos psicológicos } \\
\text { e afetivos (Zarit Burden Interview) }\end{array}$} & \multicolumn{5}{|c|}{$\begin{array}{r}\text { Grupo de Cuidadoras Profissionais }(n=15) . \\
\text { Dados descritos em valor percentual. }\end{array}$} & \multicolumn{5}{|c|}{$\begin{array}{l}\text { Grupo de Cuidadoras Familiares }(n=5) \text {. } \\
\text { Dados descritos em valor percentual. }\end{array}$} \\
\hline & 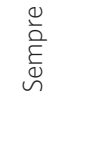 & 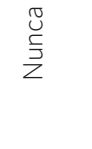 & 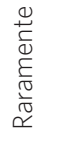 & 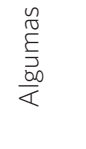 & 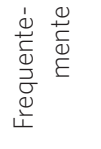 & 产 & $\begin{array}{l}\stackrel{0}{5} \\
\stackrel{5}{Z}\end{array}$ & 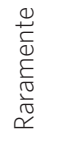 & 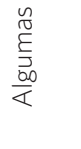 & 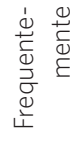 \\
\hline $\begin{array}{l}\text { A senhora sente que o idoso pede mais ajuda do que } \\
\text { necessita? }\end{array}$ & 13,3 & 53,3 & 6,7 & 26,7 & - & - & 80 & - & 20 & . \\
\hline $\begin{array}{l}\text { A senhora sente que, por causa do tempo que gasta } \\
\text { com o idoso, não tem tempo para si mesma? }\end{array}$ & - & 80 & 6,7 & 6,7 & 6,6 & - & 100 & - & - & \\
\hline $\begin{array}{l}\text { A senhora se sente estressada entre cuidar do idoso } \\
\text { e de suas outras responsabilidades com a família e o } \\
\text { trabalho? }\end{array}$ & - & 67 & - & 33 & - & 20 & 80 & - & - & \\
\hline $\begin{array}{l}\text { A senhora se sente envergonhada com o comporta- } \\
\text { mento do idoso? }\end{array}$ & 6 & 67 & 26 & - & - & - & 100 & - & - & \\
\hline $\begin{array}{l}\text { A senhora se sente irritada quando o idoso está por } \\
\text { perto? }\end{array}$ & - & 86,67 & - & 13,33 & - & - & 100 & - & - & \\
\hline $\begin{array}{l}\text { A senhora sente que o idoso afeta negativamente } \\
\text { seus relacionamentos com outros membros da famí- } \\
\text { lia ou amigos? }\end{array}$ & - & 80 & - & 10 & 10 & 20 & 60 & 20 & - & \\
\hline A senhora sente receio pelo futuro do idoso? & 33 & 7 & 7 & 53 & - & - & 20 & - & 60 & 20 \\
\hline A senhora sente que o idoso depende da senhora? & 47 & 7 & 7 & 12 & 27 & - & 40 & - & 20 & 40 \\
\hline $\begin{array}{l}\text { A senhora se sente tensa quando o idoso está por } \\
\text { perto? }\end{array}$ & - & 100 & - & - & - & - & 100 & - & - & \\
\hline $\begin{array}{l}\text { A senhora sente que sua saúde foi afetada por causa } \\
\text { do seu envolvimento com o idoso? }\end{array}$ & 6,7 & 80 & 6,7 & 6,6 & - & 40 & 40 & & 20 & \\
\hline $\begin{array}{l}\text { A senhora sente que não tem tanta privacidade } \\
\text { como gostaria por causa do idoso? }\end{array}$ & - & 86 & 7 & 7 & - & 20 & 40 & - & - & 40 \\
\hline $\begin{array}{l}\text { A senhora sente que sua vida social tem sido prejudi- } \\
\text { cada em razão de ter de cuidar do idoso? }\end{array}$ & - & 93 & - & 7 & - & 20 & 60 & - & - & 20 \\
\hline $\begin{array}{l}\text { A senhora não se sente à vontade em receber visitas } \\
\text { em casa por causa do idoso? }\end{array}$ & - & 80 & 10 & 10 & - & 20 & 80 & - & - & \\
\hline $\begin{array}{l}\text { A senhora sente que o idoso espera que a senhora } \\
\text { cuide dele como se fosse a única pessoa de quem ele } \\
\text { pode depender? }\end{array}$ & 27 & - & - & 40 & 33 & 20 & 40 & 20 & - & 20 \\
\hline $\begin{array}{l}\text { A senhora sente que não tem dinheiro suficiente } \\
\text { para cuidar do idoso somando-se as suas outras } \\
\text { despesas? }\end{array}$ & - & 100 & - & - & - & - & 80 & - & 20 & \\
\hline $\begin{array}{l}\text { A senhora sente que será incapaz de cuidar do idoso } \\
\text { por muito mais tempo? }\end{array}$ & 7 & 53 & - & 33 & 7 & - & 60 & 20 & 20 & \\
\hline $\begin{array}{l}\text { A senhora sente que perdeu o controle de sua vida } \\
\text { desde a doença do idoso? }\end{array}$ & - & 60 & 10 & 20 & 10 & 20 & 60 & - & 20 & \\
\hline $\begin{array}{l}\text { A senhora gostaria de simplesmente deixar que outra } \\
\text { pessoa cuidasse do idoso? }\end{array}$ & - & 86 & 7 & 7 & - & - & 100 & - & - & \\
\hline $\begin{array}{l}\text { A senhora se sente em dúvida sobre o que fazer pelo } \\
\text { idoso? }\end{array}$ & 7 & 27 & 33 & 33 & - & - & 40 & - & 40 & 20 \\
\hline $\begin{array}{l}\text { A senhora sente que deveria estar fazendo mais pelo } \\
\text { idoso? }\end{array}$ & 33 & 13 & 7 & 47 & - & 20 & 40 & - & 40 & \\
\hline A senhora sente que poderia cuidar melhor do idoso? & 7 & 23 & 7 & 33 & 30 & 20 & 40 & - & 40 & \\
\hline $\begin{array}{l}\text { De uma maneira geral, quanto a senhora se sente } \\
\text { sobrecarregada por cuidar do idoso? }\end{array}$ & - & 67 & 27 & 6 & - & 40 & 60 & - & - & . \\
\hline
\end{tabular}


Utilizou-se o Meem com a intenção de rastrear a função cognitiva das entrevistadas. O ponto de corte do escore utilizado foi de 24 pontos para indivíduos que apresentavam nove anos ou mais de estudo, e de 17 pontos para aqueles com menos tempo de estudo. Encontraram-se duas cuidadoras profissionais que possuíam nove anos ou mais de estudo com escore abaixo de 24 pontos, e uma cuidadora deste mesmo grupo com menos de nove anos de estudo e escore abaixo de 17 pontos. Esses dados mostram que $20 \%$ do total das cuidadoras profissionais apresentavam alterações ao Meem. Do grupo de cuidadoras familiares, $100 \%$ das entrevistadas se encontravam com sinais cognitivos sem alteração.

No que diz respeito à Escala de Depressão Geriátrica Abreviada, entre as cuidadoras de idosos profissionais, $80 \%$ foram avaliadas com depressão leve, e $20 \%$ foram consideradas normais. No grupo de cuidadoras de parentes idosos, quatro foram classificadas dentro do escore de depressão leve, e uma classificada dentro do escore de normalidade.

A escala do Equilíbrio e da Marcha de Tinneti é utilizada para avaliar as condições vestibulares e de marcha no ser humano (FIGUEIREDO; LIMA; GUERRA, 2007). Observou-se que em ambos os grupos nenhuma apresentava risco para quedas.

\section{Discussão}

É visível o crescimento progressivo da população em fase de envelhecimento no Brasil e em outros locais no mundo. O número de idosos fragilizados aumenta por adoecimento e perda de autonomia, demandando cuidados de terceiros no ambiente familiar (CRUZ; HAMDAN, 2008). O maior número de pesquisas realizadas no continente europeu demonstra um envelhecimento generalizado, registrando, inclusive, uma importante mudança na dinâmica populacional (FREIRE, ET AL., 2017). Além disso, esses cuidados podem ser complexos e necessários por longos períodos de tempo (PAVARINI; LOUREIRO; SOUZA, 2011; SOUZA, 2016), que é onde se inserem as redes formais ou informais de cuidado à pessoa idosa. As primeiras, compostas por cuidadores profissionais pagos, e as segundas, por cuidadores familiares que realizam o cuidado sem remuneração (MARIGLIANO ET AL., 2015). Na presente pesquisa, observou-se que 15 cuidadoras de idosos eram assalariadas, e 5 cuidavam de familiares sem pagamento. No Brasil (SouzA, 2016) e em outras culturas (MARIGLIANO ET AL., 2015), é comum que esses cuidados sejam realizados pela família, sendo o domicílio o espaço escolhido (PAVARINI; LOUREIRO; SOUZA, 2011; SOUZA, 2016). Porém, devido às novas configurações sociais, tem aumentado a contratação de serviços de terceiros para a realização desses cuidados, demandando, assim, a capacitação desses profissionais (MARIGLIANO ET AL., 2015). O cuidador do idoso deveria ser uma pessoa capacitada e que fizesse o elo entre o idoso e a família, o serviço de saúde ou a comunidade (souzA, 2005). Nesse contexto, o amadurecimento de políticas públicas que focalizem a tarefa do cuidador no domicílio favorece a qualidade do profissional cuidador (ELOIA ETAL., 2014). No entanto, nem sempre esse cuidador possui qualificação para exercer tal tarefa, conforme demonstrado no presente estudo, em que se observou que todas as cuidadoras de idosos pesquisadas, embora trabalhassem na área há anos, como profissionais ou não, não tiveram orientações ou capacitação para exercer essa função. Além disso, a escolaridade prevalente entre as cuidadoras de idosos foi o ensino médio completo, e já foi demonstrado que a escolaridade pode influenciar a qualidade da assistência ao idoso, pois

o cuidador precisa seguir dietas, ler bulas de remédios, entender dosagens e via de administração para melhor prover o cuidado, além da valorização e da conscientização sobre a importância na prevenção de doenças na terceira idade. (ARAÚJO; OLIVEIRA; PEREIRA, 2012, P. 122). 
Esses dados são preocupantes uma vez que a qualidade de vida do idoso requer uma visão ampliada de suas necessidades, e a falta de conhecimento pode levar ao sofrimento do idoso no ambiente familiar, nos aspectos social, econômico e afetivo. A qualidade do cuidado depende de um contexto que envolve o uso de tecnologias, saberes e recursos adequados e que ajudará o idoso a enfrentar suas dificuldades (souzA, 2005), de onde se depreende que todos os cuidadores necessitam de informação, educação, encorajamento e suporte (CRUZ; HAMDAN, 2008). De certo modo, uma vez que algumas cuidadoras de idosos que participaram deste estudo buscaram a Day Home, com a finalidade de orientação, e relataram que, sempre que podem, buscam elucidação para suas dúvidas, mesmo que em fontes não científicas, fica claro que elas se preocupam em buscar informações a respeito do cuidado.

Vários motivos podem contribuir para que um indivíduo seja eleito o cuidador do ente envelhecido, podendo ser citados os fatores geracionais, de gênero, grau de parentesco, morar na mesma casa que o idoso, ter condições financeiras, dispor de tempo, a ausência de outras pessoas para a tarefa de cuidar, a criação de laços afetivos, a relação de intimidade entre o idoso e o possível cuidador, a proximidade geográfica entre eles, a personalidade do cuidador, sua história de relacionamento com o idoso e com outros membros da família, sua motivação e sua capacidade de doação (PAVARINI; LOUREIRO; SOUZA, 2011). Segundo Hirata e Guimarães (2012), todas as ocupações do care têm uma predominância feminina. Certas ocupações do care, como empregadas domésticas e cuidadoras, reforçam não apenas a desigualdade de gênero, mas, também, as de classe social e raça, parecendo haver a regência de um princípio de desigualdade. Neste trabalho, muitas cuidadoras assalariadas relataram que ocuparam essa função ao acaso e por necessidade financeira, embora a maioria tenha revelado exercer o ofício por opção, com relação às cuidadoras que não recebem remuneração. Já entre as cuidadoras de familiares envelhecidos, nenhuma delas optou pela tarefa, e todas afirmaram que se sentiam na 'obrigação' de cuidar de mãe/pai ou sogra por serem parentes, corroborando outros achados (PAVARINI; LOUREIRO; SOUZA, 2011; SOUZA, 2016).

Observou-se neste estudo que a amostra foi constituída apenas por mulheres, fossem elas pagas para esse serviço ou não. Foi demonstrado, no Brasil e na Itália, que o cuidado ao idoso é comumente realizado pelas domésticas/diaristas que mantêm o trabalho doméstico e o cuidado, integrando o grupo de cuidadoras assalariadas. Além disto, ratifica a ideia de que fica ao encargo das mulheres o papel de cuidadora domiciliar de idosos. Oliveira e colaboradores (2006) demonstraram em seu estudo que $70,3 \%$ dos cuidadores entrevistados eram mulheres. Ainda, Santos e Pavarini (2010) observaram que, em geral, quem desempenha as tarefas de cuidar na família é a mulher, uma vez que essa função é, historicamente, pertencente a ela, enquanto ao homem cabe o sustento dessa instituição. Isso gera uma situação de cuidado informal, considerado uma prestação de cuidados a indivíduos familiares dependentes, que não é remunerada. Esse cuidador informal torna-se o 'profissional oculto' do cuidado ao idoso, experienciando consequências que repercutem na sua qualidade de vida e na do idoso (MARIGLIANO ET AL., 2015).

Neste trabalho, observou-se que as cuidadoras de idosos tinham entre 51 e 60 anos. É comum o cuidador pertencer à mesma faixa etária do doente, isto é, idosos independentes cuidando de idosos dependentes (CRUZ; HAMDAN, 2008), embora jovens também possam ocupar essa função. Esse predomínio permite relacionar que os próprios cuidadores poderão apresentar complicações com o cuidado de si mesmos, pois, já em idade de envelhecimento, o cuidador também é uma pessoa frágil ou em vias de ficar doente (ARAÚJO; OLIVEIRA; PEREIRA, 2012). 
Com relação ao estado civil, este estudo demonstrou que 8 das cuidadoras eram casadas e 12 eram solteiras, divorciadas ou viúvas. Araújo, Oliveira e Pereira (2012) verificaram que a maioria dos cuidadores estudados em sua pesquisa possuía relações estáveis e cuidava de idosos, o que pode resultar em sobrecarga de atividades devido à gerencia do lar, uma vez que os cuidadores acreditavam que cuidar era um trabalho difícil, gerava sobrecarga e resultava em cansaço, insônia e problemas de saúde.

A respeito do que mais agrada as cuidadoras profissionais ou familiares entrevistadas neste estudo em sua ocupação, a maioria respondeu que se sente útil e gratificada com a troca de afeto, o convívio e a aprendizagem com o idoso. Carneiro e França (2011, P. 649) apontam "que o crescimento pessoal, o senso de autorrealização e o sentimento de gratificação são benefícios decorrentes do ato de cuidar". A tarefa de cuidar pode trazer satisfação pessoal, realização e habilidade para enfrentar novos desafios, além de melhorar o relacionamento com o idoso e gerar sentimento de retribuição. Contudo, sabe-se que o cuidador tem de superar desafios para exercer com precisão o seu papel (GAIOLl; FUREGATO; SANTOS, 2012), uma vez que ele fica muitas horas ao lado do paciente (ARaújo; Oliveira; PeReIRA, 2012). Por esse motivo, o cuidar pode trazer sentimentos ambíguos: o altruísmo e a gratificação e o desgaste de lidar com fatores estressantes (MARIGLIANO ET AL., 2015). Isso fica evidenciado no presente estudo, pois a maioria das cuidadoras de idosos pesquisadas gostaria de trocar/revezar/deixar essa função, em virtude da 'teimosia' do idoso, por se sentir cobrada pela família/sociedade, pela baixa remuneração (quando recebem salário) e pelo excesso de trabalho. Ainda, a maioria admitiu já ter se irritado com os idosos de quem cuida. É importante ressaltar que a 'teimosia' do idoso é o principal motivo em casos de maus tratos, em situações extremas, reforçando a ideia de que a falta de informação específica dificulta as relações entre idoso e cuidador, favorecendo situações de risco no cuidado e levando à violência doméstica. Esses conflitos interpessoais podem ser minorados pela educação dos cuidadores, evidenciando que há solução para os fatores estressantes (CARNEIRO; FRANÇA, 2011).

$\mathrm{O}$ presente estudo demonstrou que as cuidadoras profissionais e familiares trabalham, em média, seis dias, de 12 a 24 horas. O quadro é agravado no caso de cuidadoras de idosos familiares já que residem junto ao ente envelhecido, referindo a falta de folgas. Assim, muitas relatam sobrecarga pela Escala de ZBI. A experiência de assumir o papel de cuidador familiar é exaustiva e estressante, pelo envolvimento afetivo e pela relação de dependência, quando o cuidador passa a ter restrições com relação à sua própria vida. Isso também pode ocorrer pelo tempo e pela dedicação despendidos pelos cuidadores e pelas condições de fragilidade física e mental de alguns idosos, o excesso de solicitação de cuidados, o humor difícil e o criticismo do idoso, o que exige do cuidador atenção, carinho e cuidado físico, comprometendo o autocuidado (SANTOS; PAVARINI, 2010). Por esse motivo, é importante uma boa formação técnica fundamentada em conceitos teóricos, humanísticos e éticos, pois a sobrecarga emocional vivenciada pelo cuidador pode interferir no cuidado prestado (SANTOS; PAVARINI, 2010) e/ou levar o cuidador ao desenvolvimento de doenças (MARIGLANO ET AL., 2015). Assim, o suporte aos cuidadores é um desafio para o sistema de saúde brasileiro, justificando, também, a necessidade de estudos sobre essa temática (SOUZA; WEGNER; GORINI, 2007).

Por seu caráter estressante, cuidar de idosos pode contribuir para o aparecimento de sintomas como depressão, baixa autoestima, dificuldade para lidar com frustração, sensação de desamparo, intolerância e culpa (TOMOMITSU; LEMOS; PERRACINI, 2010). O Meem sinaliza transtornos neurológicos (FOLSTEIN; FOLSTEIN; MCHUGH, 1975) e, neste estudo, apontou três cuidadoras com possível 
déficit cognitivo e/ou indícios do começo de demência, o que sugere a necessidade de exames complementares para que se possa obter um diagnóstico. No Brasil, já foram descritas associações entre o baixo escore do Meem, a baixa escolaridade e a idade avançada, sendo que a idade é um dos determinantes mais importantes do declínio cognitivo (VALLE Et AL., 2009). Em outros países, foram encontradas essas mesmas associações e a presença de sintomas depressivos (ANDERSON ET AL., 2007). Os resultados do presente trabalho estão de acordo com tais observações, pois o grupo estudado apresentava idade avançada e baixa escolaridade; além disso, também se verificou que $80 \%$ das cuidadoras de idosos profissionais e familiares apresentaram sintomas compatíveis com depressão leve, por aplicação da Escala de Depressão Geriátrica. Cuidadores podem apresentar estresse e menor nível de satisfação em viver, comparados à população em geral, havendo associação entre idosos muito dependentes e cuidadores com altos níveis de depressão (ZAUTRA; HALL; MURRAY, 2008). Porém, Gaioli e colaboradores (2012) observaram que a resiliência está correlacionada com a baixa somatização e depressão, propocionado pela melhora da saúde física, sensação de bem-estar e habilidade para lidar com problemas. A religiosidade também é uma estratégia eficaz de enfrentamento da sobrecarga de cuidado, da angústia, do estresse e da depressão (PAULA; ROQUE; ARAÚJO, 2008).

Alguns cuidadores do presente estudo relataram queixas de esquecimento, em decorrência da idade, corroborando outros autores. Isso pode ocorrer em virtude do envelhecimento e do estresse apresentado pelo tipo de população estudada. Tais fatos angustiam os cuidadores, pois eles são responsáveis pelo cuidado e permanecem muito tempo sozinhos com os idosos. O grande desafio é lidar com o surgimento das doenças no cuidador, pelo fato de estarem envelhecendo, o que justifica a necessidade da colaboração de outras pessoas para a manutenção do cuidado (GAIOLI; FUREGATO; SANTOS, 2012). O ideal era que a família fosse inserida no cuidado, a fim de diminuir as sobrecargas individuais, evitando transformar o cuidador em alguém que venha a necessitar de cuidados futuramente (ARAúJo ET AL., 2013).

A vulnerabilidade biológica, a prestação de cuidados físicos e o estresse prolongado podem aumentar o risco de problemas de saúde entre os cuidadores de idosos (TOMOMITSU; LEMOS; PERRACINI, 2010). Em uma sociedade que envelhece cada vez mais, é fundamental estar atento às condições dos cuidadores de idosos para que não ocorram desfechos negativos em termos de saúde. No presente estudo, verificou-se que a maioria das cuidadoras de idosos se encontra com IMC de sobrepeso (20\%) e obesas (35\%). A obesidade é um risco sério para doenças crônicas, entre as quais, hipertensão, doenças cardiovasculares e diabetes tipo 2 (SALVE, 2006). Além disso, a maioria das cuidadoras relatou sofrer de dores articulares e lombares, que podem ter sido causadas por posicionamentos impróprios ao movimentar seus pacientes. Resende e Dias (2008, P. 179) afirmam que a

alta porcentagem de problemas de coluna pode estar relacionada com atividades diárias de cuidados com os idosos, que envolvem o uso da força muscular e, muitas vezes, posturas inadequadas.

Além disso, diversas enfermidades incapacitam o idoso em suas atividades, e isso pode levá-lo a apresentar dificuldades no equilíbrio e na marcha, facilitando quedas. Esse foi o motivo pelo qual optou-se por avaliar o equilíbrio e a marcha das cuidadoras participantes deste trabalho, pelo protocolo de Tinnetti. Nenhuma cuidadora estudada apresentou risco para quedas, embora todas já tivessem mais de 50 anos, reforçando a importância da manutenção da saúde do indivíduo cuidador. 


\section{Conclusões}

Por meio dos resultados obtidos neste trabalho, encontraram-se subsídios que reforçam a necessidade de investigações e inovações nos saberes e fazeres na área do envelhecimento, principalmente em seus cuidados. Segundo Souza e colaboradores (2007, P. 270),

conhecer quem é o cuidador de idosos e qual o universo em que ele transita pode contribuir para a elaboração de um plano de ação que aumente sua capacidade de cuidar a si e ao outro.

A sociedade ainda está à mercê de cuidadores de idosos despreparados, como ficou demonstrado neste trabalho. Além disto, constata-se que a saúde encontra-se comprometida em grande parte deles, o que faz supor estar aumentada a probabilidade de riscos na execução de suas tarefas.

Por fim, a elaboração desta pesquisa oportuniza a reflexão sobre que importância está sendo dada ao cuidador que auxilia na diminuição do número de internações hospitalares ou do isolamento do idoso, seja domiciliar ou institucionalmente, num contingente que só aumenta no mundo.

\section{Colaboradores}

Todos os autores contribuíram substancialmente para a concepção, o planejamento e a análise e a interpretação dos dados, assim como para a elaboração e a aprovação da versão final deste manuscrito.

\section{Referências}

ANDERSON, T. M. et al. Effects of sociodemographic and health variableson Mini-Mental State Exam scores in older Australians. American Association for Geriatric Psychiatry, Washington, DC, v. 15, n. 4, p. 67-76, 2007. Disponível em: <https://www.ncbi.nlm.nih.gov/pubmed/17545447>. Acesso em: 2 jan. 2017.

ARAÚJO, C. L. O.; OLIVEIRA, J. F. O.; PEREIRA, J. M. Perfil de cuidadores de idosos com Doença de Alzheimer. Kairos Gerontologia, São Paulo, v. 15, n. 2, p. 119-137, 2012. Disponível em: <https://revistas.pucsp. br/index.php/kairos/article/view/13109>. Acesso em: 2 jan. 2017

ARAÚJO, J. S. et al. Perfil dos cuidadores e as dificuldades enfrentadas no cuidado ao idoso, em Ananindeua,
PA. Revista Brasileira de Geriatria e Gerontologia, Rio de Janeiro, v. 16, n. 1, p. 149-158, 2013. Disponível em: <http://www.scielo.br/scielo.php?pid=S1809$-98232013000100015 \&$ script=sci_abstract\&tlng=pt $>$. Acesso em: 2 jan. 2017.

CARNEIRO, V. L.; FRANÇA, L. H. F. P. Conflitos no relacionamento entre cuidadores e idosos: o olhar do cuidador. Revista Brasileira de Geriatria e Gerontologia, Rio de Janeiro, v. 14, n. 4, p. 647-662, 2011. Disponível em: <http://www.scielo.br/pdf/rbgg/v14n4/a05v14n4. pdf $>$. Acesso em: 2 jan. 2017.

CRUZ, M. N.; HAMDAN, A. C. O. Impacto da Doença de Alzheimer no cuidador. Psicologia em Estudo, Maringá, v. 13, n. 2, p. 223-229, 2008. Disponível em: 
<http://www.scielo.br/pdf/pe/vl3n2/a04v13n2>. Acesso em: 2 jan. 2017.

ELOIA, S. C. Sobrecarga do cuidador familiar de pessoas com transtorno mental: uma revisão integrativa. Saúde em Debate, Rio de Janeiro, v. 38, n. 103, p. 9961007, 2014. Disponível em: <http://www.scielo.br/scielo.php?pid=S0103-11042014000400996\&script=sci abstract\&tlng=pt $>$. Acesso em: 2 jan. 2017.

FIGUEIREDO, K. M.; LIMA, K. C.; GUERRA, R. O. Instrumentos de avaliação do equilíbrio corporal em idosos. Revista Brasileira de Cineantropometria \& Desempenho Humano, Florianópolis, v. 9, n. 4, p. 408413, 2007. Disponível em: <https://www.researchgate. net/publication/259675327_INSTRUMENTOS_DE_ AvALIACAO_DO_EQUILIBRIO_CORPORAL_EM_ IDOSOS>. Acesso em: 2 jan. 2017.

FLETCHER, R. H.; FLETCHER, S. W.; FLETCHER, G. S. Epidemiologia Clínica: Elementos Essenciais. 5. ed. Porto Alegre: Artmed, 2014.

FOLSTEIN, M. F.; FOLSTEIN, S. E.; MCHUGH, P. R. Mini-Mental State: a practical method for grading the cognitive state of patients for the clinician. Journal of Psychiatric Research, Oxford, v. 12, p. 189-98, 1975. Disponível em: <https://www.ncbi.nlm.nih.gov/pubmed/1202204>. Acesso em: 2 jan. 2017.

FREIRE, J. C. G. et al. Fatores associados à fragilidade em idosos hospitalizados: uma revisão integrativa. Saúde em Debate, Rio de Janeiro, 2017. Disponível em: $<$ http://www.saudeemdebate.org.br/artigos/artigo_int. php?id_artigo=4995 $>$. Acesso em: 2 jan. 2017. No prelo.

GAIOLI, C. C. L. O.; FUREGATO, A. R. F.; SANTOS,

J. L. F. Perfil de cuidadores de idosos com doença de Alzheimer associado à resiliência. Revista Texto $\mathcal{G}$ Contexto Enfermagem, Florianópolis, v. 21, n. 1, p. 150157, 2012. Disponível em: <http://www.scielo.br/pdf/ tce/v21nl/al7v21n1.pdf >. Acesso em: 2 jan. 2017.

HIRATA, H.; GUIMARÃES, N. A. (Org.). Cuidado e cuidadoras: as várias faces do trabalho do care. São Paulo: Atlas, 2012.
MARIGLIANO, R. X. et al. Estratégias de autocuidado usadas por cuidadores de idosos: análise de produção científica. Mudanças Psicologia da Saúde, São Paulo, v. 23, n. 2, p. 37-45, 2015. Disponível em: <https://www. metodista.br/revistas/revistas-metodista/index.php/ MUD/article/view/6435/5273>. Acesso em: 2 jan. 2017.

OLIVEIRA, S. K. et al. Perfil dos cuidadores de idosos atendidos pelo Projeto Assistência Interdisciplinar a Idosos em Nível Primário - PAINP, Londrina-PR. Ciência, Cuidado e Saúde, Maringá, v. 5, n 2, p.184-92, 2006. Disponível em: <http://periodicos.uem.br/ojs/index.php/CiencCuidSaude/article/view/5074 >. Acesso em: 2 jan. 2017.

PARADELA, E. M. P.; LOURENÇO, R. A.; VERAS, R. P. Validação da escala de depressão geriátrica em um ambulatório geral. Revista de Saúde Pública, São Paulo, v. 39, n. 6, p. 918-923, 2005. Disponível em: <http:// www.scielo.br/scielo.php?script=sci_arttext\&pid =S0034-89102005000600008>. Acesso em: 2 jan. 2017.

PAULA, J.; ROQUE, F.; ARAÚJO, F. Qualidade de vida em cuidadores de idosos portadores de demência de Alzheimer. Jornal Brasileiro de Psiquiatria, Rio de Janeiro, v. 57, n. 4, p. 283-287, 2008. Disponível em: <http://www.scielo.br/scielo.php?pid=S0047$-20852008000400011 \&$ script $=$ sci_abstract $\&$ tlng $=$ pt $>$. Acesso em: 2 jan. 2017.

PAVARINI, G.; LOUREIRO, C. P.; SOUZA, D. H. Compreensão de emoções, aceitação social e avaliação de atributos comportamentais em crianças escolares. Psicologia: Reflexão e Crítica, Porto Alegre, v. 24, n. 1, p.135-143, 2011. Disponível em: <http://dx.doi. org/10.1590/S0102-79722011000100016>. Acesso em: 5 jan. 2017.

REBOUÇAS, M.; PEREIRA, M. G. Indicadores de saúde para idosos: comparação entre o Brasil e os Estados Unidos. Revista Panamericana de Salud Pública, Whashington, DC, v. 23, n. 4, p. 237-246, 2008. Disponível em: <http://www.scielosp.org/pdf/rpsp/ v23n4/v23n4a03>. Acesso em: 2 jan. 2017.

RESENDE, M. C. F.; DIAS, E. C. Cuidadores de idosos: um novo/velho trabalho. Physis: Revista de 
Saúde Coletiva, Rio de Janeiro, v. 18, n. 4, p. 785-800, 2008. Disponível em: <http://www.scielo.br/scielo. php?pid=S0103-73312008000400010\&script=sci abstract\&tlng=pt>. Acesso em: 2 jan. 2017.

SALVE, M. G. C. Obesidade e Peso Corporal: riscos e consequências. Movimento e Percepção, Espírito Santo do Pinhal, v. 6, n. 8, p. 29-48, 2006. Disponível em: <http://www.educadores.diaadia.pr.gov.br/arquivos/File/2010/artigos_teses/2010/Ciencias/Artigos/ Obesidade_consequencias.pdf>. Acesso em: 2 jan. 2017.

SANTOS, A. A.; PAVARINI, S. C. I. Perfil dos cuidadores de idosos com alterações cognitivas em diferentes contextos de vulnerabilidade social. Revista Gaúcha de Enfermagem, Porto Alegre, v. 31, n. 1, p. 115-122, mar. 2010. Disponível em: <http:// www.scielo.br/scielo.php?script=sci_arttext\&pid =S1983-14472010000100016>. Acesso em: 2 jan. 2017.

SEQUEIRA, C. A. C. Adaptação e validação da Escala de Sobrecarga do Cuidador de Zarit. Revista Referência, [S. 1.], v. 2, n. 12, p. 9-16, 2010. Disponível em: <http:// www.index-f.com/referencia/2010pdf/12-0916.pdf >. Acesso em: 2 jan. 2017.

SOUZA, N. R. Olhar sobre o cuidador de idosos dependentes. Revista Saúde.com, [S. 1.], v. 1, n. 1, p. 51-59, 2005 Disponível em: <http://www.uesb.br/revista/rsc/ojs/ index.php/rsc/article/view/18>. Acesso em: 2 jan. 2017.

SOUZA, S. O planejamento do autocuidado para o cuidador de idosos: revisão integrativa Revista de Enfermagem, Recife, v. 10, n. 5, p. 1866-1872, 2016. Disponível em: <https://periodicos.ufpe.br/revistas/ revistaenfermagem/article/viewFile/13567/16357>. Acesso em: 2 jan. 2017.
SOUZA, L. M.; WEGNER, W.; GORINI, M. I. C. P. Educação em saúde: uma estratégia de cuidado ao cuidador Leigo. Revista Latino-americana de Enfermagem, Ribeirão Preto, v. 15, n. 2, 2007. Disponível em: $<$ http://www.scielo.br/scielo.php?pid=S0104$-11692007000200022 \&$ script $=$ sci_abstract\&tlng=pt $>$. Acesso em: 2 jan. 2017.

TOMOMITSU, M. R. S. V.; LEMOS, N. D.; PERRACINI, M. R. Prevalência e fatores associados à fragilidade em cuidadores idosos. Geriatrics, Gerontology and Aging; Rio de Janeiro, v. 4, n. 1, p. 3-12, 2010. Disponível em: <http://ggaging.com/details/292/pt-BR/prevalence-and-associated-factors-to-frailty-among-senior-caregivers>. Acesso em: 2 jan. 2017.

VALLE, E. A. et al. Estudo de base populacional dos fatores associados ao desempenho no Mini Exame do Estado Mental entre idosos: Projeto Bambuí. Cadernos de Saúde Pública, Rio de Janeiro, v. 25, n. 4, p. 918-926, 2009. Disponível em: < http://www. scielo.br/scielo.php?script=sci_arttext $\&$ pid=S0102-311X2009000400023>. Acesso em: 2 jan. 2017.

ZAUTRA, A. J.; HALL, J. S.; MURRAY, K. E. Resilience: a new integrative approach to health and mental health research. Health Psychology Review, [S. 1.], v. 2, n. 1, p. 41-64, 2008. Disponível em: <http://www.tandfonline. com/doi/abs/10.1080/17437190802298568>. Acesso em: 2 jan. 2017.

\footnotetext{
Recebido para publicação em março de 2017

Versão final em julho de 2017

Conflito de interesses: inexistente

Suporte financeiro: não houve
} 